\title{
Split atlas: reporte de un caso
}

\section{Split Atlas: A Case Report}

\author{
Andrés Y. Vásquez ${ }^{1}$ Patricia Eugenia Gil-Serrano ${ }^{2}$ Jheison Vallejo Díaz ${ }^{3}$ \\ 1 Residente de Radiología, Universidad de La Sabana, Chía, Colombia \\ 2 Radióloga, Universidad CES, Medellín, Colombia \\ 3 Médico Neuroradiólogo, Centro Médico Imbanaco, Cali, Colombia \\ Address for correspondence Andrés Y. Vásquez, Residente de \\ Radiología, Universidad de La Sabana, Chía, Colombia
}

Rev Argent Radiol 2019;83:59-61.

Estimados editores,

La ausencia parcial o completa del arco anterior y posterior del atlas es una anomalía congénita con una baja incidencia. Eso se genera por una fusión incompleta de los arcos vertebrales derivados del mesodermo. ${ }^{1,2}$

Comunicamos el caso de una paciente de 27 años de edad, sin antecedentes patológicos, quien consultó a neurología por cuadro clínico de más de 1 año de evolución consistente en cefalea asociado a dolor cervical de moderada intensidad de forma episódica el cual aumentaba con la actividad física. Se realizó una tomografía computada de cráneo simple sin evidencia de alteraciones intracraneanas, solo con un hallazgo en la región cervical de ausencia de fusión de los hemiarcos anteriores y posteriores del atlas, configurando un Split atlas (-Figs. 1 y 2 ).

La ausencia parcial o completa de fusión del arco anterior y posterior del atlas es una anomalía congénita poco frecuente. $^{2,3}$ Tiene una incidencia del 0,69-2,95\%, usualmente es asintomático y su diagnóstico la mayoría de las veces es incidental. ${ }^{2,4}$

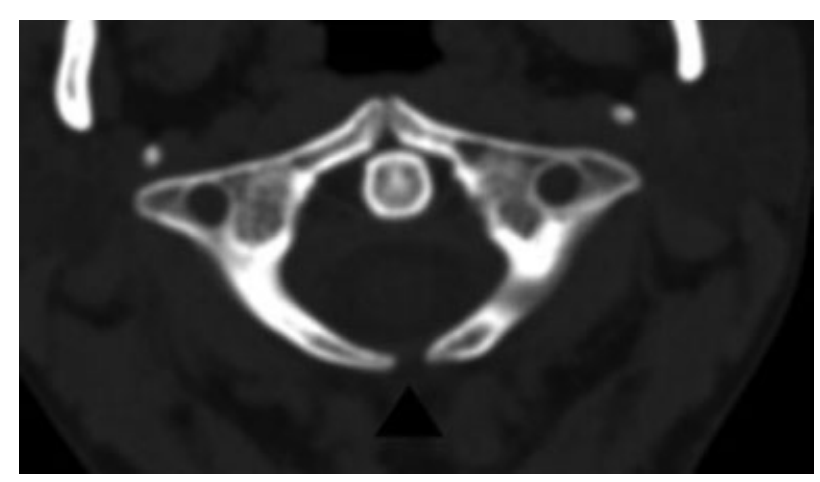

Fig. 1 Tomografía computada cerebral en ventana para hueso. Muestra defecto de fusión de los dos hemiarcos de la línea media del atlas (cabeza de flecha).

received

March 28, 2018

accepted

November 20, 2018
DOI https://doi.org/

$10.1055 / \mathrm{s}-0038-1676642$. ISSN 1852-9992.
El origen embriológico del atlas (C1) se deriva del mesodermo desde la tercera semana de gestación, dicho mesodermo se separa en grupos de somitas que se diferencian en esclerotomas ventromediales 0 dermomiotomas dorsolaterales. Los esclerotomas son los que se diferenciarán en cuerpos vertebrales los cuales desarrollan arcos que tienen tres centros de osificación para formar el atlas: el anterior, que forma el tubérculo anterior y dos laterales, que se extienden hacia la región dorsal para formar el arco posterior. ${ }^{5}$ En el momento del nacimiento, el arco anterior y posterior se encuentran con pocos milímetros de cartílago a punto de fusionarse, ocurriendo finalmente dicha fusión entre los 3 y los 5 años de edad; a pesar de eso, la fusión incompleta de los arcos puede ser normal hasta los 10 años. ${ }^{2-4}$ Se considera que los defectos de fusión de los arcos ocurren por una falla en la condrogénesis local secundaria a una alteración de la osificación de los arcos laterales dado por la formación de hendiduras mediales o algún grado de displasia. ${ }^{4}$

Se ha descrito una clasificación anatómica de los defectos de fusión principalmente del arco posterior del atlas, donde el tipo A es el más frecuente en un $90 \%$ de los casos con hallazgo de falla en la fusión de los hemiarcos de la línea media posterior, el tipo B con defecto unilateral, tipo C defecto bilateral, tipo D con ausencia del arco posterior, con persistencia del tubérculo posterior y tipo $\mathrm{E}$ con ausencia del arco completo. ${ }^{3,6,7}$ (Tabla 1).

Comúnmente, los pacientes no presentan síntomas, pero el defecto puede desencadenar dolor cervical crónico, cefalea, el signo de Lhermitte (sensación de parestesia en los brazos, secundario a la flexión voluntaria o pasiva del cuello) e incluso mielopatía cervical en casos severos, en especial en la clasificación C y D. ${ }^{2}$

La radiografía, tomografía computada incluyendo la reconstrucción en 3D y la resonancia magnética son herramientas útiles para la evaluación de esa anomalía

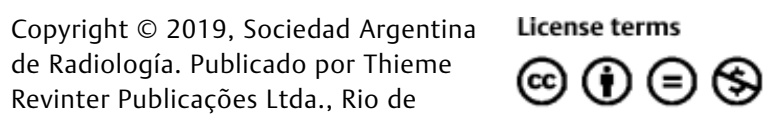
Revinter Publicações Lta., Rio de reservados. 

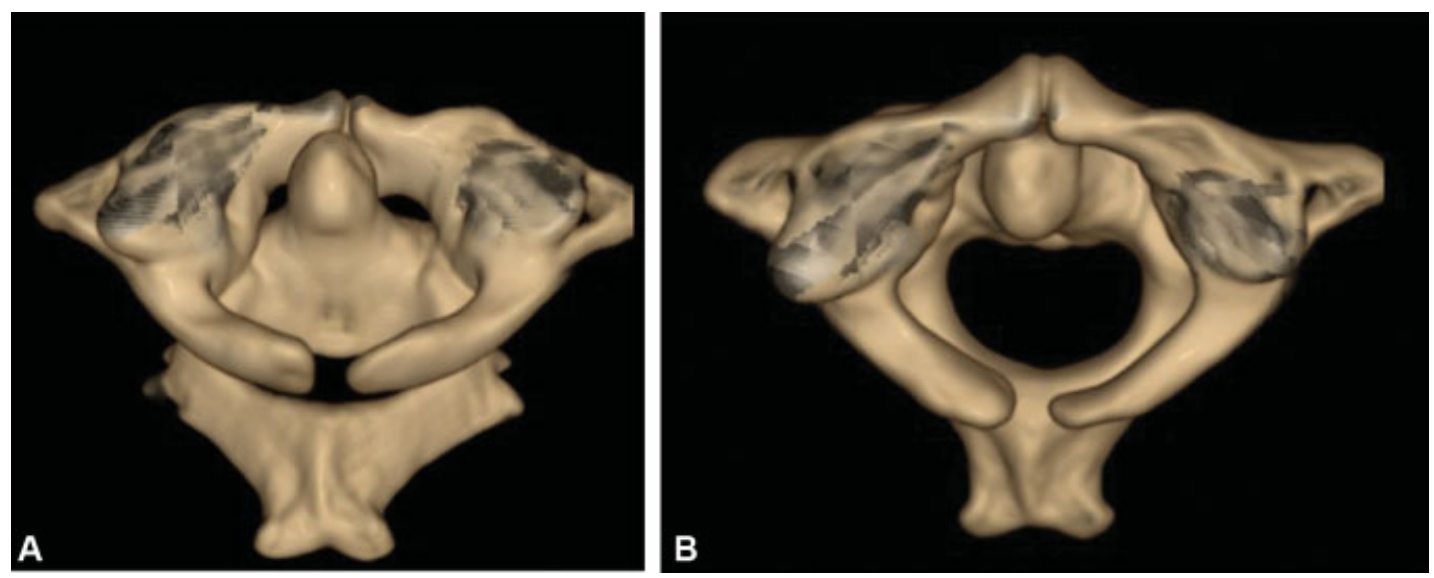

Fig. 2 Tomografía computada cerebral con representación de volumen (volume rendering) muestra (A) vista superior y (B) vista posterior ausencia de fusión de los dos hemiarcos de la línea media del atlas.

Tabla 1 Clasificación de las anomalías del arco posterior del atlas de Currarino

\begin{tabular}{|l|l|}
\hline Tipo & Malformación correspondiente \\
\hline A & $\begin{array}{l}\text { Falla en la fusión de los dos hemiarcos de } \\
\text { la línea media posterior }\end{array}$ \\
\hline B & Defecto unilateral \\
\hline C & Defecto bilateral \\
\hline D & $\begin{array}{l}\text { Ausencia del arco posterior, con persistencia } \\
\text { del tubérculo posterior }\end{array}$ \\
\hline E & $\begin{array}{l}\text { Ausencia del arco completo, } \\
\text { incluyendo el tubérculo }\end{array}$ \\
\hline
\end{tabular}

congénita. Aunque suele ser un hallazgo incidental, se puede tener una aproximación diagnóstica con una radiografía cervical lateral en flexión y en extensión donde se detectan casos de inestabilidad mecánica y se tiene una aproximación de la movilidad de un tubérculo aislado; la tomografía computada puede brindar una determinación precisa de la magnitud de la anomalía tanto en 2D como en 3D, proporcionando una clara valoración de la columna cervical superior y un excelente contraste entre la porción osificada y la no osificada del arco posterior de $\mathrm{C} 1$, se puede observar el Split atlas con los bordes de los arcos de fusión incompletos, lisos, con pared cortical intacta sin presencia de edema óseo ni de los tejidos blandos adyacentes, ${ }^{2,4}$ en los casos que se asocian a sintomatología neurológica se realiza la resonancia magnética ya que tiene mayor sensibilidad para la valoración de la médula espinal, estructuras adyacentes y tejidos blandos paraespinales evidenciando hallazgos como mielomalacia focal o edema de cordón. ${ }^{1,4}$

Es importante diferenciar esa variante anatómica, sobre todo en el contexto de trauma cervical ya que puede simular una fractura de Jefferson o luxación, ${ }^{2,8}$ que ocurren con un mecanismo de carga axial a través del occipucio, generando una distracción de las masas laterales del atlas, aumentando la tensión en el anillo de la vértebra que posteriormente se fractura en los puntos más débiles, que son los puntos de unión entre el arco posterior y anterior. ${ }^{5}$ En las imágenes, las fracturas pueden evidenciar bordes irregulares, no esclerosos, asociado a edema de tejidos blandos adyacentes, que comprometen el arco anterior, posterior, ambas o las masas laterales. ${ }^{2,5}$

En cuanto al manejo, la intervención quirúrgica solo se considera en los casos de inestabilidad atlanto-axoidea y compromiso del cordón espinal. En el resto de los casos el manejo es conservador, con analgesia y terapia física. ${ }^{2,4} \mathrm{Sin}$ embargo, algunos autores recomiendan intervenir los tipos $C$ y D para evitar lesión acumulativa espinal ya que esos tipos son los que generan en la mayoría de los casos, la cuadriparesia transitoria. $^{2}$

En conclusión, el Split atlas es un defecto en el desarrollo embriológico del arco anterior y posterior del atlas poco frecuente, suele ser asintomático por lo que en la mayoría de los casos es un hallazgo incidental. Sin embargo, debe ser una alternativa diagnóstica en casos sintomáticos en los que no se ha encontrado causa aparente de dolor cervical, por eso el apoyo en imágenes diagnósticas con una interpretación rigurosa es fundamental para el enfoque clínico.

\section{Confidencialidad de los Datos}

Los autores declaran que han seguido los protocolos de su centro de trabajo sobre la publicación de datos de pacientes, y que todos los pacientes incluidos en el estudio han recibido información suficiente y han dado su consentimiento informado por escrito para participar en dicho estudio.

\section{Conflicto de Intereses}

Los autores declaran no tener ningún conflicto de intereses.

\section{Bibliografía}

1 Smoker WR. Craniovertebral junction: normal anatomy, craniometry, and congenital anomalies. Radiographics 1994;14 (02):255-277 
2 Park Y, Kim SM, Lee YT, et al. Congenital anomaly of the atlas misdiagnosed as posterior arch fracture of the atlas and atlantoaxial subluxation. Clin Orthop Surg 2014;6(01): 96-100

3 Sharma A, Gaikwad SB, Deol PS, Mishra NK, Kale SS. Partial aplasia of the posterior arch of the atlas with an isolated posterior arch remnant: findings in three cases. AJNR Am J Neuroradiol 2000;21 (06):1167-1171

4 Sabuncuoglu H, Ozdogan S, Karadag D, Kaynak ET. Congenital hypoplasia of the posterior arch of the atlas: case report and extensive review of the literature. Turk Neurosurg 2011;21(01): 97-103
5 Offiah CE, Day E. The craniocervical junction: embryology, anatomy, biomechanics and imaging in blunt trauma. Insights Imaging 2017; 8(01):29-47

6 Currarino G, Rollins N, Diehl JT. Congenital defects of the posterior arch of the atlas: a report of seven cases including an affected mother and son. AJNR Am J Neuroradiol 1994;15(02):249-254

7 Quinteiro Antolín T, Castellano Romero I, Yáñez Calvo J. [Aplasia of the posterior arches of the atlas: a presentation of 2 cases]. Rev Esp Cir Ortop Traumatol 2012;56(05):381-384

8 Bonneville F, Jacamon M, Runge M, Jacquet G, Bonneville JF. Split atlas in a patient with odontoid fracture. Neuroradiology 2004;46 (06):450-452 